\title{
Ossa Martínez, M. A. (2017). Repertorio, historia y vivencias en la retaguardia: la Banda Municipal de Música de Cuenca en la guerra civil española. Albacete: Uno Editorial, 306 pp. ISBN: 978-84-17055-61-5.
}

Estamos ante una interesante publicación denominada La Banda Municipal de Música de Cuenca en la Guerra Civil Española: Repertorio, historia y vivencias en la retaguardia, del musicólogo Marco Antonio de la Ossa Martínez (Cuenca, 1978). Además de investigador, de la Ossa es maestro en Educación Musical, licenciado en Historia y Ciencias de la Música, posee un máster en Gestión Cultural y es doctor en Bellas Artes. También es funcionario del cuerpo de maestros en la especialidad de educación musical desde 2001 y profesor asociado en el Departamento de Expresión Musical, Plástica y Corporal de la Universidad de Castilla- La Mancha en la Facultad de Educación de Cuenca. Obtiene el "Premio de Investigación Musical y Estudios Musicológicos” de la Sociedad Española de Musicología (2009) por su magnífica tesis doctoral. El resumen de la misma fue titulado La música en la guerra civil española (Cuenca, Madrid: Servicio de Publicaciones de la Universidad de CastillaLa Mancha/SEdEM, 2011). Tras el importante galardón continua su trayectoria escribiendo La lectura musical a primera vista (Cuenca, CeLeO Editorial: 2013); Ángel, musa y duende: Federico García Lorca y la música (Cuenca/Madrid, Servicio de Publicaciones de la Universidad de Castilla-La Mancha/Alpuerto, 2014); y La educación musical en la educación primaria: claves para el acceso a la función pública docente (CeLeO Editorial, 2015). Tras las anteriores publicaciones, el autor vuelve a centrarse en el periodo histórico que comprende la guerra civil. Esta vez lo hace de la mano de la Banda Municipal de Cuenca, su ciudad natal. Durante los años de la guerra a la banda se la conoció como: Banda de Música de Cuenca. Este nuevo trabajo de Marco Antonio de la Ossa nos sumerge en la crudeza de la guerra, utilizando como vehículo la función musical y social que desempeñaba la agrupación conquense en la época. Podemos decir que este nuevo trabajo de Marco Antonio de la Ossa, se posiciona como una obra de referencia dentro de las publicaciones que tratan la función de las bandas de música durante el conflicto bélico. De una lectura amena y ligera, pero con el rigor que caracteriza al autor, el musicólogo aborda aspectos de especial interés dentro de una de las agrupaciones más particulares del panorama español, la cual, se mantuvo en terreno republicano hasta el final de la guerra.

Al comenzar a navegar entre sus páginas nos encontramos con el primer capítulo. En él se narra una introducción histórica basada en la importancia e influencia de la música para el ser humano a través de los siglos. El arte de Euterpe ha acompañado al hombre en celebraciones o festejos, pero también ha desarrollado un papel fundamental en guerras y revoluciones. Este hecho está reflejado en algunas citas que de forma cuidada nos muestra el autor en este primer capítulo: "Casi todas las guerras y revoluciones se hacen al son de 
cánticos y músicas, por paradójico que esto pueda parecer" (Viana, 1985, pp. 40-41). Como consecuencia, la música se convierte en un instrumento de gran poder a la hora de servir como canalizador de ideales en la guerra civil española. Los himnos y cánticos sirven para grabar en la conciencia de quienes los escuchan el mensaje que se quiere transmitir. La guerra a la que se enfrentaron los españoles, tal y como nos señala de la Ossa, fue horrenda. Este libro transciende lo puramente musical y nos hace ser conscientes de la importancia que tiene el conocimiento para poder superar el pasado: "solo podrá ser enterrado cuando se conozca claramente la verdad respecto al mismo. Por eso creo que la preocupación por la historia contemporánea en la España moderna tiene que ser terapéutico" (Thomas, 1976, p. 21).

Con estas y otras ideas en torno a la guerra civil comienza el primer capítulo de la obra que avanza hacia un análisis de la importancia las bandas de música en España. Hay que destacar que las bandas de música siempre fueron populares en nuestro país. Como bien señala el musicólogo, eran organizaciones sociales presentes en todos los pueblos, que ayudaban a mantener la identidad cultural. Las bandas de música acompañaban distintos acontecimientos sociales como podían ser fiestas patronales, celebraciones o maniobras militares. De alguna forma estas formaciones musicales siempre estuvieron relacionadas con la actividad militar. El autor describe en su libro cómo desde tiempos del Cid Campeador ya existía esta relación. A lo largo de unas interesantes citas reflejadas en el libro, nos da a conocer cómo en el año 711 el caudillo árabe Tarik, invasor de España, contaba con un cuerpo de timbaleros que precedía a sus tropas (Adam, 1986, p. 10). Los sonidos de estos instrumentos tenían una clara función intimidatoria. En el libro también se plasma la importancia de las bandas militares en la época napoleónica, las cuales estaban nutridas de hasta una veintena de músicos. Pues bien, la guerra civil no se quedó atrás y compartió dicha práctica. Marco Antonio de la Ossa nos hace un buen resumen de todo ello en el capítulo 3 y desgrana los entresijos de bandas de ciudades como Barcelona o Madrid.

En el capítulo 4 se realiza un breve recorrido a través de la historia de la Banda de Música de Cuenca, donde se expone las particularidades de la misma. Así, la Banda de Música nace en un contexto bélico, ya que su primer objetivo fue la recaudación de fondos para las familias de los soldados que combatían en las guerras españolas de las últimas colonias (1896). Posteriormente, la agrupación se incorpora de la mano de distintos directores a la vida social de la ciudad, y realiza diferentes funciones en celebraciones o actos de carácter religioso como la Semana Santa.

En el capítulo 5 se continúa narrando la historia de la Banda Municipal de Cuenca, pero dentro del ámbito de la guerra civil española. Durante esta sección se plasma la labor de la agrupación en zona republicana. El hecho de que su actividad tuviera lugar en esta zona, tuvo como consecuencia que algunos documentos fueran destruidos antes de la llegada de las tropas nacionalistas. Si avanzamos a través de las páginas de este capítulo, nos encontramos con la organización de la banda en cinco estratos y los nombres de los músicos en esa época. También se registran las altas y bajas de algunos de ellos, producidas por la llamada a filas en distintas brigadas. Una cuestión muy importante que se narra en el capítulo 5 es cómo el director de la Banda Jesús Calleja comunicó al Ayuntamiento estas 


\section{RESEÑAS DE LIBROS}

altas y las bajas de los músicos entre 1936 y 1939, así, como las devoluciones o solicitudes de instrumentos por parte de algunos integrantes. Se dio el caso de músicos que, tras su baja, no devolvieron los instrumentos o que pidieron algunos de ellos prestados a la agrupación. El autor del libro nos explica que la falta de instrumentos durante la guerra civil fue una constante, para muchos instrumentistas poseer un instrumento les proporcionaba una especie de "pasaporte" para acceder a las bandas de distintos estamentos militares. Durante la guerra fue importante saber tocar algún instrumento de viento o percusión, ya que este hecho permitía acceder a las bandas de distintos batallones sin empuñar el arma durante la guerra.

El capítulo 6 versa sobre la represión y los expedientes especiales para la depuración que sufrieron miembros de la Banda de Cuenca. Aquellos miembros que tenían una plaza como funcionarios del ayuntamiento fueron sometidos a investigaciones sumarias con el objetivo de conocer su grado de implicación con la república, la izquierda o la masonería. Algunos de ellos fueron absueltos, pero otros se enfrentaron a expedientes y suspensiones de empleo y sueldo. Estas condenas también podían hacerlos ingresar en prisión o costarles la vida.

Por último, en el capítulo 7 se realiza un amplio análisis de las canciones e himnos que se encontraban en el archivo de la Banda de Música de Cuenca, así como aquellos que aparecen en las hemerotecas de la época. Algunos de ellos fueron interpretados durante la guerra y otros como Cara al sol fueron introducidos en el repertorio tras la contienda. En los análisis se incluye la partitura con la melodía principal., la letra, la contextualización y procedencia o creación de los distintos himnos. Analizados por el autor encontramos himnos tanto del bando republicano como del Frente Popular: iA las barricadas!, El pendón morado, El Quinto Regimiento, El tren blindado, Els segadors, el Himno de Riego, La Internacional, La Joven Guardia, La Komintern, La Marsellesa, Marcha del Quinto Regimiento, Puente de los Franceses, Cara al sol, El novio de la muerte y la Marcha Granadera.

Tras este breve análisis del libro de Marco Antonio de la Ossa, no podemos más que invitar a los lectores interesados en el contexto histórico de la Guerra Civil Española, así como a los estudiosos de las bandas de música, a adentrarse y recorrer las páginas de esta publicación. Un libro muy recomendable en el que se suceden acontecimientos, anécdotas y datos de relevancia, combinado con un aire fresco y lectura ligera sin perder el rigor en su escritura. Estamos además ante una obra capaz de despertar en el lector el deseo de ahondar en la música y contexto de una época que como dice el autor fue "uno de los instantes más dramáticos y horrendos de la historia de la humanidad” (Ossa Martínez, 2017, p. 11). Un momento histórico del que siempre es bienvenido conocer nuevos datos, para no repetir los errores del pasado y ser un poco más libres.

\section{BIBLIOGRAFÍA}

Adam Ferrero, B. (1986). Las bandas de música en el mundo. Madrid: Ediciones Sol.

Thomas, H. (1976). La Guerra Civil Española. Barcelona: Grijalbo Mondadori. 
RESEÑAS DE LIBROS

Díaz Viana, L. (1985). Canciones populares de la Guerra Civil. Madrid: Taurus Ediciones.

Silvia Nogales Barrios

Universidad de Castilla-La Mancha

ORCID ID: https://orcid.org/0000-0003-4941-4565 